Article

\title{
Understanding the Eco-Friendly Role of Drone Food Delivery Services: Deepening the Theory of Planned Behavior
}

\author{
Jinsoo Hwang ${ }^{1}{ }^{(\mathbb{D}}$, Insin Kim $^{2, *}$ and Muhammad Awais Gulzar ${ }^{3}(\mathbb{D}$ \\ 1 The College of Hospitality and Tourism Management, Sejong University, 98 Gunja-Dong, Gwanjin-Gu, \\ Seoul 143-747, Korea; jhwang@sejong.ac.kr \\ 2 Department of Tourism and Convention, Pusan National University, Busan 43241, Korea \\ 3 Waikato Management School, University of Waikato, Hamilton 3240, New Zealand; \\ awais.gulzar@waikato.ac.nz \\ * Correspondence: sini0721@naver.com
}

Received: 22 January 2020; Accepted: 11 February 2020; Published: 15 February 2020

check for updates

\begin{abstract}
This study tried to explain consumer's intention formation in the context of drone food delivery services based on Ajzen's theory of planned behavior (TPB) model. In addition, this study tried to deepen the TPB by understanding the moderating effect of the awareness of consequences. The data were collected from 406 respondents using an online survey in South Korea. The results showed that all proposed hypotheses were accepted. It was also found that the awareness of consequences plays a crucial role in the relation between perceived behavioral control and behavioral intentions. Important theoretical and managerial implications are discussed in the last part of the paper.
\end{abstract}

Keywords: drone food delivery services; theory of planned behavior; awareness of consequences; behavioral intentions

\section{Introduction}

Environmental management is an important issue in the restaurant industry. Currently, restaurant companies are using motorcycles or cars to deliver food. However, they are regarded as the main cause of environmental pollution, because they emit much exhaust gas. In particular, consumers are concerned about environmental pollution [1,2], so they try to buy environmentally friendly products/services [3,4]. Drone food delivery services (DFDS) are offered as a method in order to solve such problems. DFDS are in the early stages of commercialization, so they are limited in some areas. For example, Costa Coffee in Dubai uses drones on the beach to make it easier to deliver coffee to customers [5]. More importantly, DFDS are more environmentally friendly than existing delivery methods, such as cars or motorcycles; because DFDS are powered by electrical energy they are expected to help protect the natural environment [6]. For this reason, currently, DFDSs are receiving a lot of attention from many restaurant companies.

It is necessary to identify the consumer decision-making process to enhance their positive behavioral intentions (BI), which is considered to be most important to firms' long-term success $[7,8]$. Furthermore, understanding the consumer decision-making process plays an important role in developing more efficient and effective marketing strategies $[9,10]$. Therefore, many of the existing studies in various fields have put in a lot of effort to understand how to form consumer decision using the theory of planned behavior (TPB) [11-14]. TPB was first proposed by Ajzen [15] and is known as an extended model of the theory of reasoned action (TRA). TRA considers only volitional factors, such as attitude and the subjective norm (SN), to explain an individual's behavioral intention, whereas TPB 
extends TRA by adding non-volitional factors (i.e., perceived behavioral) in order to predict consumer behavior more accurately [16,17]. Thus, TPB is deemed a more comprehensive model of TRA [18].

According to Ajzen, the TPB model is not sufficient to fully understand consumer behavior in a new field, so it is better to modify the original constructs of TPB by including additional variables. Based on Ajzen's suggestion, this study tried to deepen the TPB model by identifying the moderating role of the awareness of consequences in the context of DFDS because pro-environmental behavior is greatly influenced by the level of awareness of consequences $[19,20]$. Hence, much previous research has examined the moderating role of the awareness of consequences in green research, which suggests that it is significant to identify the differences in consumer behavior according to the level of awareness of consequences [21,22]. Therefore, an investigation of the moderating effect of the awareness of consequences within the TPB model will provide a good understanding of an individual's BI in the context of DFDS.

Overall, the current study aimed at applying TPB to explain the formation of consumers' intention to use DFDS. More specifically, this study (1) investigated the effect of three salient belief items, including behavioral, normative, and control beliefs on each predictor of BI, including attitude, SN, and perceived behavioral control (PBC) and (2) investigated the moderating role of the awareness of consequence within the proposed theoretical framework. The results of this study are expected to provide useful insights for restaurant companies preparing to use DFDS, because the services will be activated in the future and play a big role in environmental protection. Furthermore, to the best of our knowledge, this study investigates influencing factors on behavioral intention formation using ТРВ in the context of DFDS for the first time, so the findings of this paper would also be significant and meaningful in the theoretical aspect.

\section{Literature Review}

\subsection{Elicitation Study}

Based on Ajzen and Fishbein [17], new sets of beliefs and salient referents were developed using an elicitation study and validation of the theory's belief constructs for the context of DFDS. First, this study conducted a focus group as an elicitation method [23-25]. The following three groups participated in this method: (1) three professors with a main research focus on restaurants, (2) three restaurant managers, and (3) three drone experts. As a result, 12 items for beliefs, including behavioral beliefs (BB), normative beliefs (NB), and control beliefs (CB) were suggested. In addition, 12 items for evaluative components, which included outcome evaluation (OE), motivation to comply (MC), and perceived power (PP), were derived from the focus group and the literature review. Within the case of the salient referents, family/relatives, friends, and colleagues/co-workers were included.

After developing the initial questionnaire, a pretest was performed based on 50 actual restaurant customers based on online surveys in South Korea. Respondents did not know about DFDS, because the services have not been commercialized in South Korea, so about two minutes of newspaper articles that explained the environment-friendly role of DFDS were given to the respondents before the survey. And the results revealed that the measurement items had satisfactory levels of reliability and validity.

\subsection{Belief Constructs}

Three measurement items were used to measure behavioral beliefs using a seven-point Likert-type scale that ranged from strongly disagree (1) to strongly agree (7). Three measurement items were employed to measure the outcome evaluations with a seven-point Likert-type scale. In addition, normative beliefs were measured based on three measurement items that used a 7-point Likert-type scale $(1=$ very false; $7=$ very true). Motivation to comply was measured with three items. The items were anchored on a seven-point Likert-type scale ( $1=$ extremely unlikely; $7=$ extremely likely). In the case of control beliefs, three measurement items were employed with a seven-point Likert-type scale that ranged from strongly disagree (1) to strongly agree (7). Lastly, perceived power was measured 
based on three measurement items that used a seven-point Likert-type scale. As Azjen [15] suggested, the overall level of each belief construct was obtained by multiplying all items for each belief with its corresponding evaluative components (i.e., $\Sigma \mathrm{BBiOEi}, \Sigma \mathrm{NBj} \mathrm{MCj}$, and $\Sigma \mathrm{CBkPPk}$ ).

\subsection{Attitude toward A Behavior (ATB)}

In the TPB model, ATB is postulated as the first predictor of BI, and it is defined as "the degree to which a person has a favorable or unfavorable evaluation or appraisal of the behavior in question" [15] (p. 188). ATB is estimated by multiplying behavioral beliefs by the corresponding outcome evaluations [26-28]. Behavioral beliefs refer to an individual's perceived likelihood of an expected result by engaging in a specific behavior, and outcome evaluations refer to the individual evaluation of the possible outcomes of a particular behavior [22,29]. More importantly, people have a favorable attitude toward a certain behavior when the outcome of the behavior is positive [15,30], which suggests the effect of ATB on BI. Empirical research also supported the relationship. For instance, Han [30] explored the effect of ATB on BI using 402 guests in a green lodging context. The author suggested ATB played a crucial function in the formation of BI. Additionally, Olya, Bagheri, and Tumer [31] examined the influence of ATB on BI using 320 guests of green hotels. Their data analysis results indicated that ATB increased BI. In other words, if consumers have a good attitude toward using a green hotel, they tend to visit the green hotel.

\subsection{Subjective Norm (SN)}

The second significant predictor of $\mathrm{BI}$ is $\mathrm{SN}$, which is defined as "the perceived social pressure to perform or not to perform the behavior" [15] (p. 188). That is, SN means an individual does not evaluate himself/herself for a certain behavior but does an evaluation of the people around him/her. According to Ajzen and Fishbein [17], SN is formed by combining normative beliefs and the motivation to comply. Normative beliefs are considered the perceived opinions of one's significant important referents towards a certain behavior, and the motivation to comply is the individual's agreement to accept the opinions of the referents [18]. Additionally, empirical studies have consistently suggested the significant role of SN as a predictor of BI. For instance, Han and Hyun [31] applied the TPB model to an environmentally responsible museum context using 429 samples. They found that SN helps to enhance BI. Additionally, Verma and Chandra [32] collected data from 295 guests to explain how SN affects BI in the context of green hotels. They suggested that $\mathrm{SN}$ is a crucial factor influencing BI.

\subsection{Perceived Behavioral Control (PBC)}

The last predictor of BI is PBC. The concept of PBC is defined as "the perceived ease or difficulty of performing the behavior" [15] (p. 122). Similar to the two predictors of the TPB model presented above, PBC can be estimated on the basis of the combination of control beliefs and perceived power [15,17]. Control beliefs mean an individual's perceived presence/absence of resources and opportunities which facilitate/impede the performance of a certain behavior and perceived power is an individual evaluation of the significance of the resources and opportunities in accomplishing behavioral results [33,34]. It is widely accepted that an individual's intention to take a particular action is dependent on how many resources or opportunities the person has $[15,33]$. Prior research has also supported the argument. For example, Chen and Tung [35] tested the relationship between PBC and behavioral intensions using 559 customers in the context of green hotels. Their data analysis results showed that PBC played a critical role in forming BI. In addition, Wang et al. [36] collected data from 324 green hotel customers to explore the relationship between PBC and behavioral intensions. They showed that PBC is a critical factor that explains BI.

\subsection{Moderating Role of Awareness of Consequences}

The concept of the awareness of consequences has been widely used to investigate consumer decision-making processes in green research [37-39]. The term awareness of consequences is used 
interchangeably with problem awareness and adverse consequences of the valued objects. Awareness of consequences refers to the extent to which someone is aware of the adverse consequences of not acting socially or environmentally for other people or other things, including animals and plants $[19,20,40]$. That is, the awareness of consequences is described at a cognitive level regarding harmful consequences for the natural environment due to environmentally unfriendly behaviors in green research [41-43]. More importantly, people who have a high awareness of consequences tend to behave pro-socially, while people with lower levels of awareness of consequences are less likely to show pro-social behavior, because they believe that ecological problems are resolved automatically $[19,20,44]$. Thus, it can be inferred that people behave differently depending on their level of awareness of consequences. For example, if people are well aware of the adverse consequences of not acting environmentally, they use an environmentally amenable service, such as DFDS, when ordering food. Empirical studies also proposed the moderating role of the awareness of consequences in green research. For example, Han and Hwang [21] examined the moderating role of the awareness of consequences using 411 visitors in an environmentally responsible convention context. They found that the awareness of consequences plays an important moderating role in the relationship between moral norm and action loyalty. In addition, Han et al. [41] investigated the important function of the awareness of consequences as a moderator using 429 visitors in the context of a museum. They showed that the effect of desire toward the behavior on the visit intention is greater in the high awareness of consequences group than in the low awareness of consequences group.

\subsection{Hypotheses}

According to the theoretical and empirical background mentioned above, nine hypotheses are presented:

Hypothesis 1 (H1). BBiOEi (i.e., behavioral beliefs $\times$ outcome evaluation) positively affects attitude towards a behavior;

Hypothesis 2 (H2). NBjMCj (i.e., normative beliefs $\times$ motivation to comply) positively affects $S N$;

Hypothesis 3 (H3). CBkPPk (i.e., control beliefs $\times$ perceived power) positively affects PBC;

Hypothesis 4 (H4). ATB positively affects BI;

Hypothesis $\mathbf{5}$ (H5). SN positively affects BI;

Hypothesis 6 (H6). PBC positively affects BI;

Hypothesis 7a (H7a). Awareness of consequences moderates the relationship between ATB and BI;

Hypothesis $\mathbf{7 b} \mathbf{( H 7 b ) . ~ A w a r e n e s s ~ o f ~ c o n s e q u e n c e s ~ m o d e r a t e s ~ t h e ~ r e l a t i o n s h i p ~ b e t w e e n ~ S N ~ a n d ~ B I ; ~}$

Hypothesis 7c (H7c). Awareness of consequences moderates the relationship between PBC and BI.

\section{Methodology}

\subsection{Questionnaire Development}

In order to measure the concepts presented in this study, a questionnaire was developed using the following procedures. Items for the other constructs of TPB including ATB, SN, PBC, and BI, were cited from previous research $[15-17,32,45]$ In addition, the awareness of consequences was measured using three measurement items adapted from De Groot and Steg [19] and Han [30]. All measurement 
items were slightly revised to fit the context of DFDS. All concepts used in this study except for attitude towards a behavior were measured using a seven-point Likert-type scale $(1=$ strongly disagree; 7 = strongly agree). With the case of ATB, three bipolar semantic differential scales were used (e.g., "Unfavorable" (1)-“Favorable" (7)).

\subsection{Data Collection}

A web-based survey was conducted for the main data collection. Questionnaires were sent to 4525 panels using a market research company in South Korea. Before beginning the questionnaire, which was conducted in the pretest, respondents read articles related to the positive impact of drone food delivery service on the environment, and then they responded to the questionnaire. As a result, a total of 442 restaurant customers who have used food delivery services within six months participated in the survey. In addition, 36 samples were excluded from the statistical analysis due to visual inspections and multicollinearity problems. Finally, the statistical analysis was performed based on 406 samples.

\section{Data Analysis and Results}

\subsection{Descriptive Statistics}

Of the 406 respondents, $47.8 \%(n=194)$ were male and $52.2 \%(n=212)$ were female. The mean age of respondents was 37.71 years old. In addition, the majority of respondents reported that their monthly household income was between US $\$ 1001$ and US $\$ 2000(27.8 \%, n=113)$. In terms of participants' marital status, $51.2 \%$ of respondents $(n=208)$ were single, while married persons were $48.3 \%(n=196)$. Lastly, with regard to their education, a majority indicated that they held a bachelor's degree $(63.3 \%$, $n=257)$.

\subsection{Measurement Model}

First, the measurement model was evaluated before conducting structural equation modeling (SEM). Table 1 provides the results of the measurement model. The confirmatory factor analysis (CFA) results showed that the measurement model satisfactorily fits the data $\left(\chi^{2}=445.674, \mathrm{df}=168, \chi^{2} / \mathrm{df}\right.$ $=2.653, p<0.001$, normed fit index $(\mathrm{NFI})=0.955$, comparative fit index $(\mathrm{CFI})=0.971$, Tucker-Lewis index $(\mathrm{TLI})=0.964$, root mean square error of approximation $($ RMSEA $)=0.064)$ (Hair et al., 2006). All of the factor loadings were significant at $p<0.001$ and equal to or greater than 0.693 .

Table 1. Confirmatory factor analysis: Items and loadings.

\begin{tabular}{|c|c|}
\hline Construct and Scale Item & Standardized Loading a \\
\hline \multicolumn{2}{|c|}{ Behavioral beliefs (BB) * Outcome evaluations (OE) } \\
\hline $\mathrm{BB}_{\mathrm{i}} \mathrm{OE}_{\mathrm{i}} 1$ & 0.910 \\
\hline $\mathrm{BB}_{\mathrm{i}} \mathrm{OE}_{\mathrm{i}} 2$ & 0.945 \\
\hline $\mathrm{BB}_{\mathrm{i}} \mathrm{OE}_{\mathrm{i}} 3$ & 0.941 \\
\hline \multicolumn{2}{|c|}{ Normative beliefs (NB) * Motivation to comply (MC) } \\
\hline $\mathrm{NB}_{\mathrm{j}} \mathrm{MC}_{\mathrm{j}} 1$ & 0.959 \\
\hline $\mathrm{NB}_{\mathrm{j}} \mathrm{MC}_{\mathrm{j}} 2$ & 0.969 \\
\hline $\mathrm{NB}_{\mathbf{j}} \mathrm{MC}_{\mathrm{j}} 3$ & 0.970 \\
\hline \multicolumn{2}{|l|}{ Control beliefs $(\mathrm{CB}) *$ Perceived power $(\mathrm{PP})$} \\
\hline $\mathrm{CB}_{\mathrm{k}} \mathrm{PP}_{\mathrm{k}} 1$ & 0.775 \\
\hline $\mathrm{CB}_{\mathrm{k}} \mathrm{PP}_{\mathrm{k}} 2$ & 0.952 \\
\hline $\mathrm{CB}_{\mathrm{k}} \mathrm{PP}_{\mathrm{k}} 3$ & 0.693 \\
\hline \multicolumn{2}{|l|}{ Attitude toward a behavior (АTВ) } \\
\hline ATB1 & 0.853 \\
\hline ATB2 & 0.900 \\
\hline ATB3 & 0.947 \\
\hline
\end{tabular}


Table 1. Cont.

\begin{tabular}{lc}
\hline \multicolumn{1}{c}{ Construct and Scale Item } & Standardized Loading \\
\hline Subjective norm (SN) & \\
SN1 & 0.957 \\
SN2 & 0.974 \\
SN3 & 0.963 \\
\hline Perceived behavioral control (PBC) \\
PBC1 \\
PBC2 \\
PBC3 & 0.809 \\
\hline Behavioral intentions (BI) & 0.905 \\
BI1 & 0.760 \\
BI2 & \\
BI3 & 0.939 \\
\hline
\end{tabular}

Notes 1: ${ }^{a}$ All factors loadings are significant at $p<0.001$; Notes 2: Goodness-of-fit statistics: $\chi^{2}=445.674, \mathrm{df}=168$, $\chi^{2} / \mathrm{df}=2.653, p<0.001$, normed fit index $(\mathrm{NFI})=0.955$, comparative fit index $(\mathrm{CFI})=0.971$, Tucker-Lewis index $(\mathrm{TLI})=0.964$, root mean square error of approximation $($ RMSEA $)=0.064$.

The composite reliability was examined to confirm consistency among the measurement items for seven constructs (see Table 2). The values of composite reliability for the seven constructs were over 0.60 , which confirmed that all measurement items are highly consistent [46]. Furthermore, all average variance extracted (AVE) values exceeded 0.50, which indicated that there was no problem with the convergent validity [47]. Lastly, AVE values and the values of the squared correlations were compared in order to verify discriminant validity [47]. As a result, the AVE values were higher than the values of the squared correlations of all constructs, so discriminant validity is also statistically confirmed.

Table 2. Descriptive statistics and associated measures.

\begin{tabular}{|c|c|c|c|c|c|c|c|c|c|}
\hline & Mean (SD) & AVE & (1) & (2) & (3) & (4) & (5) & (6) & (7) \\
\hline (1) $\mathrm{BB}_{\mathrm{i}} \mathrm{OE}_{\mathrm{i}}$ & $5.35(0.90)$ & 0.869 & $0.952^{\mathrm{a}}$ & $0.589^{b}$ & 0.292 & 0.478 & 0.443 & 0.459 & 0.633 \\
\hline (2) $\mathrm{NB}_{\mathrm{j}} \mathrm{MC}_{\mathrm{j}}$ & $4.06(1.23)$ & 0.933 & $0.347^{\mathrm{c}}$ & 0.977 & 0.050 & 0.545 & 0.784 & 0.355 & 0.596 \\
\hline (4) Attitude toward a behavior & $4.78(1.33)$ & 0.811 & 0.228 & 0.297 & 0.001 & 0.928 & 0.497 & 0.323 & 0.725 \\
\hline (5) Subjective norm & $3.89(1.32)$ & 0.931 & 0.196 & 0.615 & 0.001 & 0.247 & 0.976 & 0.285 & 0.559 \\
\hline (6) Perceived behavioral control & $4.68(1.12)$ & 0.684 & 0.211 & 0.126 & 0.099 & 0.104 & 0.081 & 0.866 & 0.457 \\
\hline
\end{tabular}

Notes $1: \mathrm{BB}=$ behavioral beliefs, $\mathrm{OE}=$ outcome evaluations, $\mathrm{NB}=$ normative beliefs, $\mathrm{MC}=$ motivation to comply, $\mathrm{CB}$ $=$ control beliefs, and $\mathrm{PP}=$ perceived power; Notes $2: \mathrm{SD}=$ standard deviation, $\mathrm{AVE}$ = average variance extracted; Notes 3: ${ }^{a}$ composite reliabilities are along the diagonal, ${ }^{\mathrm{b}}$ correlations are above the diagonal, and ${ }^{\mathrm{c}}$ squared correlations are below the diagonal.

\subsection{Structural Model Evaluation}

Next, SEM was performed to prove the proposed hypotheses. The proposed model had an adequate fit to the data $\left(\chi^{2}=631.312, \mathrm{df}=180, \chi^{2} / \mathrm{df}=3.507, p<0.001, \mathrm{NFI}=936, \mathrm{CFI}=0.953\right.$, TLI $=0.946$, RMSEA $=0.079$ ) (Hair et al., 2006). Of the six proposed hypotheses, all hypotheses were supported $(p<0.05)$. More specifically, hypothesis 1 , which proposed the effect of $\mathrm{BB}_{\mathrm{i}} \mathrm{OE}_{\mathrm{i}}$ on attitude, was statistically supported $(\beta=0.502, p<0.05)$. In addition, $\mathrm{NB}_{\mathrm{j}} \mathrm{MC}_{\mathrm{j}}$ positively affected $\mathrm{SN}(\beta=0.784$, $p<0.05)$, which supported hypothesis 2 . As hypothesized, $\mathrm{CB}_{\mathrm{k}} \mathrm{PP}_{\mathrm{k}}$ played a significant role in the formation of $\mathrm{PBC}(\beta=0.323, p<0.05)$. Hence, hypothesis 3 was supported. Our results indicated that attitude $(\beta=0.594, p<0.05), \mathrm{SN}(\beta=0.267, p<0.05)$, and $\mathrm{PBC}(\beta=0.228, p<0.05)$ helped enhance BI. Thus, hypotheses 4,5 , and 6 were supported. The hypotheses testing results are summarized in Table 3 . 
Table 3. Standardized parameter estimates for the structural model.

\begin{tabular}{|c|c|c|c|c|c|}
\hline & & & Standardized Estimate & $t$-Value & Hypothesis \\
\hline $\mathrm{H} 1 \mathrm{BB}_{\mathrm{i}} \mathrm{OE}_{\mathrm{i}}$ & $\rightarrow$ & Attitude toward a behavior & 0.502 & $10.448^{*}$ & Supported \\
\hline $\mathrm{H} 2 \mathrm{NB}_{\mathrm{j}} \mathrm{MC}_{\mathrm{j}}$ & $\rightarrow$ & Subjective norm & 0.784 & 22.748 * & Supported \\
\hline $\mathrm{H} 3 \mathrm{CB}_{\mathrm{k}} \mathrm{PP}_{\mathrm{k}}$ & $\rightarrow$ & Perceived behavioral control & 0.323 & $5.981 *$ & Supported \\
\hline H4 Attitude toward a behavior & $\rightarrow$ & Behavioral intentions & 0.594 & 14.337 * & Supported \\
\hline H5 Subjective norm & $\rightarrow$ & Behavioral intentions & 0.267 & $7.118 *$ & Supported \\
\hline H6 Perceived behavioral control & $\rightarrow$ & Behavioral intentions & 0.228 & $5.913 *$ & Supported \\
\hline
\end{tabular}

Goodness-of-fit statistics: $\chi^{2}=631.312, \mathrm{df}=180, \chi^{2} / \mathrm{df}=3.507, p<0.001, \mathrm{NFI}=936$, CFI $=0.953, \mathrm{TLI}=0.946$,

and RMSEA $=0.079$; Notes 1: $\mathrm{BB}=$ behavioral beliefs, $\mathrm{OE}=$ outcome evaluations, $\mathrm{NB}=$ normative beliefs, $\mathrm{MC}$

$=$ motivation to comply, $\mathrm{CB}=$ control beliefs and PP $=$ perceived power; Notes $2:{ }^{*} p<0.05$; Notes $3: \mathrm{NFI}=$ normed fit index, $\mathrm{CFI}=$ comparative fit index, TLI $=$ Tucker-Lewis index, and RMSEA $=$ root mean square error of approximation.

\subsection{Moderating Role of Awareness of Consequences}

Table 4 provides the results of moderating the role of the awareness of consequences. In this study, a multiple group analysis was used to confirm the moderating role of the awareness of consequences. In order to check the differential effects of a moderating variable, the chi-square difference between the unconstrained and constrained models was evaluated in regards to the difference in the degrees of freedom [48].

Table 4. Results for the moderating role of awareness of consequences.

\begin{tabular}{|c|c|c|c|c|c|c|c|c|c|}
\hline & & \multicolumn{2}{|c|}{ The Low Group } & \multicolumn{2}{|c|}{ The High Group } & $\begin{array}{c}\text { Unconstrained } \\
\text { Model }\end{array}$ & Constrained Model & $\Delta \chi^{2}(1)=3.84$ & Hypothesis \\
\hline $\mathrm{H} 7 \mathrm{a}$ & A-BI & 0.585 & $9.494 *$ & 0.593 & 10.270 * & \multirow{2}{*}{$\chi^{2}(360)=942.377$} & $\chi^{2}(361)=943.016$ & $\Delta \chi^{2}(1)>0.639$ & Not supported \\
\hline $\mathrm{H} 7 \mathrm{c}$ & PBC-BI & 0.151 & $2.582 *$ & 0.286 & $5.350 *$ & & $\chi^{2}(361)=946.390$ & $\Delta \chi^{2}(1)<4.013$ & Supported \\
\hline
\end{tabular}

Notes 1: $\mathrm{A}=$ Attitude toward a behavior, $\mathrm{SN}=$ Subjective Norm, $\mathrm{PBC}=$ Perceived Behavioral Control, and BI = Behavioral intentions; Notes 2: * $p<0.05$.

First, the moderating role of the awareness of consequences in the relationship between attitude and BI was evaluated (H7a). The path coefficient was compared between high and low awareness of the consequences groups. The chi-square difference between the constrained and the unconstrained models was not statistically significant $\left(\chi^{2}=0.639<\chi^{2} 0.5(1)=3.84, \mathrm{df}=1\right)$, which indicated that hypothesis 7 a was not supported.

Second, the moderating role of the awareness of consequences in the relationship between $\mathrm{SN}$ and BI was assessed (H7b). The chi-square difference between the two models was not significant at the 0.05 level $\left(\chi^{2}=0.413<\chi^{2} 0.5(1)=3.84, d f=1\right)$, which did not provide any support for hypothesis $7 \mathrm{~b}$.

Lastly, the moderating role of the awareness of consequences in the relationship between PBC and $\mathrm{BI}$ was tested $(\mathrm{H} 7 \mathrm{c})$. The chi-square difference between the constrained model and the unconstrained model was significant at the 0.05 level $\left(\chi^{2}=4.013>\chi^{2} 0.5(1)=3.84, \mathrm{df}=1\right)$, which indicated that the effect of PBC on BI was significantly different across different levels of the awareness of consequences. Thus, hypothesis $7 \mathrm{c}$ was statistically supported. In terms of the low awareness of consequences group, the path coefficient between behavioral control on BI was $0.151(p<0.05)$, while the path coefficient was $0.286(p<0.05)$ for the high awareness of consequences group. Figure 1 shows the results of the SEM and the multiple group analysis. 


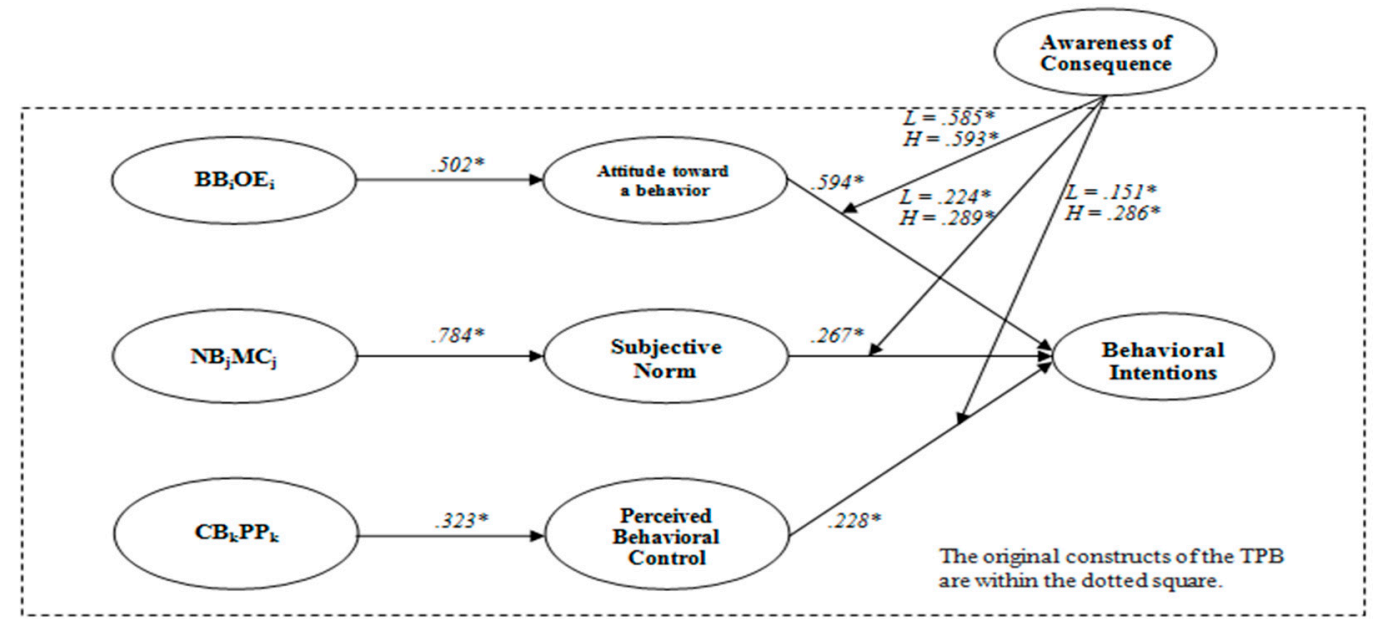

Figure 1. Results of structural equation modeling. Notes 1: Goodness-of-fit statistics: $\chi^{2}=631.312, \mathrm{df}$ $=180, \chi^{2} / \mathrm{df}=3.507, p<0.001, \mathrm{NFI}=936, \mathrm{CFI}=0.953, \mathrm{TLI}=0.946$, and RMSEA $=0.079 ;$ Notes $2: \mathrm{BB}=$ Behavioral Beliefs, $\mathrm{OE}=$ Outcome Evaluation, NB = Normative Beliefs, MC = Motivation to Comply, $\mathrm{CB}=$ Control Beliefs, and PP $=$ Perceived Power; Notes 3: ${ }^{*} p<0.05$.

\section{Discussions and Implications}

This study applied Ajzen's TPB model to the context of DFDS to explain consumers' intention formation. In addition, this study sought to deepen the TPB by understanding the moderating role of the awareness of consequences. Using an online survey in South Korea, 406 samples were collected for this. The results of the CFA showed that measurement instruments had a sufficient level of reliability and validity. In addition, the findings of a SEM indicated that all proposed hypotheses were statistically supported. The multiple group analysis also confirmed the moderating role of awareness in the relationship between PBC and BI. The findings of this study have the following important theoretical and managerial implications.

\subsection{Theoretical Implications}

This paper firstly attempted to employ the TPB model to investigate influencing factors on the formation of BI in the context of DFDS. TPB has been widely employed to explain the consumer decision-making process in various fields $[11-14,27]$ which suggests that TPB has a strong ability to explain individuals' intention formation. This study also confirmed the appropriateness of TPB in explaining an individual's behavioral intention when using DFDS. More specifically, data analysis results indicated that three belief constructs (i.e., $\mathrm{BB}_{\mathrm{i}} \mathrm{OE}_{\mathrm{i}}, \mathrm{NB}_{\mathrm{j}} \mathrm{MC}_{\mathrm{j}}$, and $\mathrm{CB}_{\mathrm{k}} \mathrm{PP}_{\mathrm{k}}$ ) have a positive influence on $\mathrm{ATB}, \mathrm{SN}$, and $\mathrm{PBC}$, respectively, which in turn positively affect $\mathrm{BI}$. The results can be interpreted to show that a favorable evaluation of the behavior, social pressures, and perceived ease of performing the behavior leads to the enhancement of the intention to use DFDS when ordering food. Previous studies also showed similar results. For instance, Montano and Kasprzyk [12] found that ATB, SN, and PBC aid the enhancement of BI. In addition, Park et al. [14] argued that ATB, SN, and $\mathrm{PBC}$ are critical predictors of BI. In comparison with existing research, the important theoretical implication of this study is that the suitability of TPB was first described in the context of DFDS.

Second, the results of the multiple group analysis showed that the awareness of consequences plays a crucial role in the relationship between $\mathrm{PBC}$ and BI. That is, consumers who are aware of the adverse consequences of not acting socially or environmentally for other people or other things are more likely to use DFDS when they recognize that it is easy to use the services. Furthermore, although it was not statistically significant, the effect of ATB and SN on behavioral intentions was greater in the high awareness of consequences group than in the low awareness of consequences group. From a theoretical aspect, these findings suggested that the three predictor variables, which included ATB, 
$\mathrm{SN}$, and PBC, are more significant in the enhancement of BI for consumers who have high levels of awareness of consequences. Although the concept of awareness of consequences has been confirmed to be of importance as a moderating role in green research [21,41], there is no research about it in the context of DFDS. In this respect, this study expanded and contributed to the current literature by empirically finding the moderating role of awareness of consequences in the context of DFDS.

\subsection{Managerial Implications}

First, this study found that ATB had a greater level of influence on BI than other predictor variables, such as SN and PBC, so restaurant companies should strive to make consumers have a favorable attitude toward DFDS. First of all, restaurant companies need to emphasize the eco-friendly aspects of DFDS through advertising, because green advertising helps to form a favorable consumer attitude toward a certain object [49]. As previously explained, DFDS run on batteries, which can reduce greenhouse gas emissions and energy use [50]. Therefore, if restaurant companies make advertisements that emphasize the important role of DFDS in protecting the environment through comparisons with current methods of delivery services, such as greenhouse gas emissions and energy use, consumers are more likely to have a favorable attitude toward the services, which leads to positive BI to use the services.

Second, the data analysis results indicated that $\mathrm{SN}$ aids to increase BI. It can be interpreted that the opinions of the people around him/her have a lot of influence on his/her behavior. From a practical aspect, it is recommended to develop a marketing strategy that allows customers to promote DFDS to their acquaintances. Recently, user-generated content (UGC) has attracted the most attention as a method for customers to participate in promoting restaurants, because UGC has about $20 \%$ more influence on purchase decisions than other media [51]. For example, many restaurant companies offer coupons to customers who post good experiences in restaurants with photos through social media, such as Facebook, Instagram, and Twitter. That is, voluntary involvement of customers in promoting their businesses is significant. Similarly, if restaurant companies use UGC to make customers promote the eco-friendly role of DFDS to other people around them, others will be greatly influenced by them. Consequently, people around them will be more likely to use DFDS when ordering food.

Third, the results of this study showed the significant moderating role of the awareness of consequences in explaining consumers' intention formation to use DFDS. From a practical standpoint, restaurant companies should make efforts to raise the awareness of environmental pollution, because consumers who know the significance of individual actions for eco-friendliness tend to use DFDS when ordering food. In fact, a lot of companies are implementing various policies in order to protect the environment, from production to sales, which help to make consumers aware of the dangers of environmental destruction $[52,53]$. In the same vein, if restaurant companies inform consumers of the risks of natural destruction through environmental campaigns, they will have high levels of the awareness of consequences, which will increase the use of DFDS.

\section{Limitations and Future Research}

This study has important theoretical and practical implications, as mentioned above, but it also has the following limitations: First, the samples of this study were collected in South Korea, so it is rather difficult to apply the results of this study to other regions. In particular, as a cross-cultural testing is very important for environmental research [54] it is necessary to verify the research model proposed in this study based on the cross-cultural test in future studies; Second, this paper focused on the context of DFDS, so the results of this study could be different if the data are collected from other industries; Third, in order to collect data, this study employed an online survey using a market research firm in South Korea. Although the convenient sampling method of using an online survey is widely used in consumer research, it can cause selection biases [55]. Therefore, it is recommended to use different data collection methods for future research; Lastly, this study successfully explained an individual's behavioral intention using the TPB model in the context of DFDS. However, it is 
recommended to consider additional predictor variables to predict customer's behavioral intention to use DFDS more accurately.

\section{Conclusions}

The results of data analysis revealed that all proposed hypotheses within the model were accepted. In terms of the moderating role of the awareness of consequences, the effect of PBC on BI was significantly different across different levels of the awareness of consequences. The current study was the first attempt to examine influencing factors on consumers' behavioral intentions using the TPB model in the context of DFDS. In addition, this study attempted to deepen the model by investigating the moderating role of the awareness of consequences for the first time. In this respect, the results of the current paper would be significant in the theoretical aspect. Furthermore, the findings of this paper provide critical practical implications for building successful DFDS.

Author Contributions: All the authors contributed to the conceptualization, formal analysis, investigation, methodology, writing of the original draft, and writing review and editing. All authors have read and agreed to the published version of the manuscript.

Funding: This work was supported by Leaders in INdustry-university Cooperation+ (LINC+), Sejong University, Korea.

Conflicts of Interest: The authors declare no conflicts of interest.

\section{References}

1. D'souza, C.; Taghian, M. Green advertising effects on attitude and choice of advertising themes. Asia Pac. J. Mark. Logist. 2005, 17, 51-66. [CrossRef]

2. Laroche, M.; Bergeron, J.; Barbaro-Forleo, G. Targeting consumers who are willing to pay more for environmentally friendly products. J. Consum. Mark. 2001, 18, 503-520. [CrossRef]

3. Han, H.; Kim, W.; Lee, S. Stimulating visitors' goal-directed behavior for environmentally responsible museums: Testing the role of moderator variables. J. Destin. Mark. Manag. 2018, 8, 290-300. [CrossRef]

4. Liu, Y.; Yang, D.; Xu, H. Factors influencing consumer willingness to pay for low-carbon products: A simulation study in China. Bus. Strategy Environ. 2017, 26, 972-984. [CrossRef]

5. The National. Watch: Drone Delivers Costa Coffee on Kite Beach in Dubai. 2017. Available online: https://www.thenational.ae/lifestyle/food/watch-drone-delivers-costa-coffee-on-kite-beach-in-dubai1.661444 (accessed on 1 December 2019).

6. Environmental Technology How Does Drone Delivery Impact the Environment? 2018. Available online: https://www.envirotech-online.com/news/environmental-laboratory/7/breaking-news/how-doesdrone-delivery-impact-the-environment/46595 (accessed on 1 December 2019).

7. Han, H.; Meng, B.; Kim, W. Emerging bicycle tourism and the theory of planned behavior. J. Sustain. Tour. 2017, 25, 292-309. [CrossRef]

8. Lewis, R.C.; Chambers, R.E. Marketing Leadership in Hospitality, Foundations and Practices, 3rd ed.; Wiley: New York, NY, USA, 2000.

9. Lee, S.; Bruwer, J.; Song, H. Experiential and involvement effects on the Korean wine tourist's decision-making process. Curr. Issues Tour. 2017, 20, 1215-1231. [CrossRef]

10. Meng, B.; Han, H. Effect of environmental perceptions on bicycle travelers' decision-making process: Developing an extended model of goal-directed behavior. Asia Pac. J. Tour. Res. 2016, 21, 1184-1197. [CrossRef]

11. Hansen, T.; Jensen, J.M.; Solgaard, H.S. Predicting online grocery buying intention: A comparison of the theory of reasoned action and the theory of planned behavior. Int. J. Inf. Manag. 2004, 24, 539-550. [CrossRef]

12. Montano, D.E.; Kasprzyk, D. Theory of reasoned action, theory of planned behavior, and the integrated behavioral model. Health Behav. Theory Res. Pract. 2015, 70, 95-124.

13. Orbell, S.; Hodgkins, S.; Sheeran, P. Implementation intentions and the theory of planned behavior. Pers. Soc. Psychol. Bull. 1997, 23, 945-954. [CrossRef] 
14. Park, S.H.; Hsieh, C.M.; Lee, C.K. Examining Chinese college students' intention to travel to Japan using the extended theory of planned behavior: Testing destination image and the mediating role of travel constraints. J. Travel Tour. Mark. 2017, 34, 113-131. [CrossRef]

15. Ajzen, I. From intentions to actions: A theory of planned behavior. In Action Control; Springer: Berlin/Heidelberg, Germany, 1985; pp. 11-39.

16. Ajzen, I. The theory of planned behavior. Organ. Behav. Hum. Decis. Process. 1991, 50, 179-211. [CrossRef]

17. Ajzen, I.; Fishbein, M. Understanding Attitudes and Predicting Social Behavior; Pearson: London, UK, 1980.

18. Han, H.; Hsu, L.T.J.; Sheu, C. Application of the theory of planned behavior to green hotel choice: Testing the effect of environmental friendly activities. Tour. Manag. 2010, 31, 325-334. [CrossRef]

19. De Groot, J.I.; Steg, L. Morality and prosocial behavior: The role of awareness, responsibility, and norms in the norm activation model. J. Soc. Psychol. 2009, 149, 425-449. [CrossRef] [PubMed]

20. Schwartz, S.H. Normative influences on altruism1. In Advances in Experimental Social Psychology; Academic Press: Cambridge, MA, USA, 1977; Volume 10, pp. 221-279.

21. Han, H.; Hwang, J. Norm-based loyalty model (NLM): Investigating delegates' loyalty formation for environmentally responsible conventions. Int. J. Hosp. Manag. 2015, 46, 1-14. [CrossRef]

22. Goodchild, A.; Toy, J. Delivery by drone: An evaluation of unmanned aerial vehicle technology in reducing $\mathrm{CO}_{2}$ emissions in the delivery service industry. Transp. Res. Part D Transp. Environ. 2018, 61, 58-67. [CrossRef]

23. Fishbein, M.; Middlestadt, S.E. Using the Theory of Reasoned Action as a Framework for Understanding and Changing AIDS-Related Behaviors; Sage: Newbury Park, CA, USA, 1989.

24. Sheppard, B.H.; Hartwick, J.; Warshaw, P.R. The theory of reasoned action: A meta-analysis of past research with recommendations for modifications and future research. J. Consum. Res. 1988, 15, 325-343. [CrossRef]

25. Shimp, T.A.; Kavas, A. The theory of reasoned action applied to coupon usage. J. Consum. Res. 1984, 11, 795-809. [CrossRef]

26. Fishbein, M.; Ajzen, I. Belief, Attitude, Intention and Behavior: An Introduction to Theory and Research; Addison-Wesley: Boston, MA, USA, 1975.

27. Meng, B.; Han, H. Investigating individuals' decision formation in working-holiday tourism: The role of sensation-seeking and gender. J. Travel Tour. Mark. 2018, 35, 973-987. [CrossRef]

28. Cheng, S.; Lam, T.; Hsu, C.H. Negative word-of-mouth communication intention: An application of the theory of planned behavior. J. Hosp. Tour. Res. 2006, 30, 95-116. [CrossRef]

29. Han, H. Travelers' pro-environmental behavior in a green lodging context: Converging value-belief-norm theory and the theory of planned behavior. Tour. Manag. 2015, 47, 164-177. [CrossRef]

30. Olya, H.; Bagheri, P.; Tumer, M. Decoding behavioural responses of green hotel guests: A deeper insight into the application of the theory of planned behaviour. Int. J. Contemp. Hosp. Manag. 2019, 31, 2509-2525. [CrossRef]

31. Han, H.; Hyun, S.S. Drivers of customer decision to visit an environmentally responsible museum: Merging the theory of planned behavior and norm activation theory. J. Travel Tour. Mark. 2017, 34, 1155-1168. [CrossRef]

32. Verma, V.K.; Chandra, B. An application of theory of planned behavior to predict young Indian consumers' green hotel visit intention. J. Clean. Prod. 2018, 172, 1152-1162. [CrossRef]

33. Azen, I.; Madden, T. Prediction of goal directed behavior: Attitudes, intentions and perceived behavioural control. J. Exp. Soc. Psychol. 1986, 22, 453-474. [CrossRef]

34. Chang, M.K. Predicting unethical behavior: A comparison of the theory of reasoned action and the theory of planned behavior. J. Bus. Ethics 1998, 17, 1825-1834. [CrossRef]

35. Chen, M.F.; Tung, P.J. Developing an extended theory of planned behavior model to predict consumers' intention to visit green hotels. Int. J. Hosp. Manag. 2014, 36, 221-230. [CrossRef]

36. Wang, J.; Wang, S.; Wang, Y.; Li, J.; Zhao, D. Extending the theory of planned behavior to understand consumers' intentions to visit green hotels in the Chinese context. Int. J. Contemp. Hosp. Manag. 2018, 30, 2810-2825. [CrossRef]

37. Jansson, J.; Marell, A.; Nordlund, A. Green consumer behavior: Determinants of curtailment and eco-innovation adoption. J. Consum. Mark. 2010, 27, 358-370. [CrossRef]

38. Kiatkawsin, K.; Han, H. Young travelers' intention to behave pro-environmentally: Merging the value-belief-norm theory and the expectancy theory. Tour. Manag. 2017, 59, 76-88. [CrossRef] 
39. Liobikienė, G.; Juknys, R. The role of values, environmental risk perception, awareness of consequences, and willingness to assume responsibility for environmentally-friendly behavior: The Lithuanian case. J. Clean. Prod. 2016, 112, 3413-3422. [CrossRef]

40. Steg, L.; De Groot, J. Explaining prosocial intentions: Testing causal relationships in the norm activation model. Br. J. Soc. Psychol. 2010, 49, 725-743. [CrossRef]

41. Han, H.; Lee, M.J.; Kim, W. Antecedents of green loyalty in the cruise industry: Sustainable development and environmental management. Bus. Strategy Environ. 2018, 27, 323-335. [CrossRef]

42. Kollmuss, A.; Agyeman, J. Mind the gap: Why do people act environmentally and what are the barriers to pro-environmental behavior? Environ. Educ. Res. 2002, 8, 239-260. [CrossRef]

43. Lee, K. Gender differences in Hong Kong adolescent consumers' green purchasing behavior. J. Consum. Mark. 2009, 26, 87-96. [CrossRef]

44. Banerjee, B.; McKeage, K. How green is my value: Exploring the relationship between environmentalism and materialism. ACR N. Am. Adv. 1994, 21, 147-152.

45. Lam, T.; Hsu, C.H. Theory of planned behavior: Potential travelers from China. J. Hosp. Tour. Res. 2004, 28, 463-482. [CrossRef]

46. Harris, K.J.; Ali, F.; Ryu, K. Foodborne illness outbreaks in restaurants and patrons' propensity to return. Int. J. Contemp. Hosp. Manag. 2018, 30, 1273-1292. [CrossRef]

47. Bagozzi, R.P.; Yi, Y. On the evaluation of structural equation models. J. Acad. Mark. Sci. 1988, 16, 74-94. [CrossRef]

48. Fornell, C.; Larcker, D.F. Structural equation models with unobservable variables and measurement error: Algebra and statistics. J. Mark. Res. 1981, 18, 382-388. [CrossRef]

49. Byrne, B.M. Structural equation modeling with AMOS, EQS, and LISREL: Comparative approaches to testing for the factorial validity of a measuring instrument. Int. J. Test. 2001, 1, 55-86. [CrossRef]

50. Marketing Insider Group 3 engagement-driving examples of B2B user generated content. 2017. Available online: https://marketinginsidergroup.com/content-marketing/3-engagement-driving-examples-b2b-usergenerated-content/ (accessed on 1 December 2019).

51. Dangelico, R.M.; Vocalelli, D. "Green Marketing": An analysis of definitions, strategy steps, and tools through a systematic review of the literature. J. Clean. Prod. 2017, 165, 1263-1279. [CrossRef]

52. Mishra, P.; Sharma, P. Green marketing: Challenges and opportunities for business. BVIMR Manag. Edge 2012, 8, 35-41.

53. Milfont, T.L.; Duckitt, J.; Wagner, C. A cross-cultural test of the value-attitude behavior hierarchy. J. Appl. Soc. Psychol. 2010, 40, 2791-2813. [CrossRef]

54. Bethlehem, J. Selection bias in web surveys. Int. Stat. Rev. 2010, 78, 161-188. [CrossRef]

55. Hartmann, P.; Apaolaza-Ibáñez, V. Green advertising revisited: Conditioning virtual nature experiences. Int. J. Advert. 2009, 28, 715-739. [CrossRef]

(C) 2020 by the authors. Licensee MDPI, Basel, Switzerland. This article is an open access article distributed under the terms and conditions of the Creative Commons Attribution (CC BY) license (http://creativecommons.org/licenses/by/4.0/). 